CLINICAL STUDY

\title{
Prevalence of cardiovascular disease and cancer during cross-sex hormone therapy in a large cohort of trans persons: a case-control study
}

\author{
K Wierckx ${ }^{1}$, E Elaut ${ }^{2}$, E Declercq ${ }^{1}$, G Heylens ${ }^{2}$, G De Cuypere $^{2}$, Y Taes ${ }^{1}$, J M Kaufman ${ }^{1}$ and G T'Sjoen ${ }^{1,2}$ \\ Departments of ${ }^{1}$ Endocrinology and ${ }^{2}$ Sexology and Gender Problems, Ghent University Hospital, De Pintelaan 185, Ghent 9000, Belgium \\ (Correspondence should be addressed to KWierckx; Email: katrien.wierckx@ugent.be)
}

\begin{abstract}
Objective: This study evaluated the short- and long-term cardiovascular- and cancer-related morbidities during cross-sex hormone therapy in a large sample of trans persons.

Subjects and methods: A specialist center cross-sectional study compared 214 trans women (male-to-female transsexual persons) and 138 trans men (female-to-male trans persons) with an age- and gender-matched control population (1-3 matching). The participants were on cross-sex hormone therapy for an average of 7.4 years. We assessed physical health and possible treatmentrelated adverse events using questionnaires.

Results: Five percent of trans women experienced venous thrombosis and/or pulmonary embolism during hormone therapy. Five of these adverse events occurred during the first year of treatment, while another three occurred during sex reassignment surgery. Trans women experienced more myocardial infarctions than the control women $(P=0.001)$, but a similar proportion compared with control men. The prevalence of cerebrovascular disease (CVD) was higher in trans women than in the control men $(P=0.03)$. The rates of myocardial infarction and CVD in trans men were similar to the control male and female subjects. The prevalence of type 2 diabetes was higher in both trans men and women than in their respective controls, whereas the rates of cancer were similar compared with the control men and women.

Conclusion: Morbidity rate during cross-sex hormone therapy was relatively low, especially in trans men. We observed a higher prevalence of venous thrombosis, myocardial infarction, CVD, and type 2 diabetes in trans women than in the control population. Morbidity rates in trans men and controls were similar, with the exception of the increased prevalence of type 2 diabetes.
\end{abstract}

European Journal of Endocrinology 169 471-478

\section{Introduction}

Hormone therapy is an established part of gender identity disorder (GID) treatment and induces secondary sex characteristic development of the desired gender while reducing that of the natal sex (1). Female-to-male transsexual persons, denoted as trans men, generally take progestins to suppress menstruation and intramuscular testosterone preparations to induce virilization. Male-to-female transsexual persons (trans women) generally take anti-androgen therapy together with oral or transdermal estrogens to induce feminization. Optimal formulations and dosages of cross-sex hormone treatment are unknown at present (2), but current guidelines recommend aiming for hormonal levels within the normal physiological range (3). Sustained supraphysiological levels of sex steroids increase the risk of adverse events such as thrombosis (3), whereas subphysiological levels may induce a hypogonadal state.
Although cross-sex hormone therapy can induce several side effects, it is surprising that only a handful of studies $(4,5,6,7,8,9)$ have examined morbidity and mortality in trans persons. In general, current evidence suggests that testosterone administration in trans men is not very harmful (10), while anti-androgen and estrogen administration may negatively impact cardiovascular health in trans women (2). Both antiandrogens and estrogens increase the risk of venous thrombosis and/or pulmonary embolism (7), and two recent mortality studies have reported a higher cardiovascular mortality rate in trans women than in the general population $(4,5)$. However, the relationship between cross-sex hormone treatment and cardiovascular risk profile in trans women is complex, as the chemical nature of the estrogens (5), the route of administration (11), the dosage of estrogens $(12,13)$, and the patient's cardiovascular health status may all have an effect. 
Cancer has not been reported frequently in trans individuals $(2,14)$. However, because some tumors are hormone dependent, examining the incidence of cancer during cross-sex hormone therapy may be important (15).

The aim of this study was to examine the prevalence of cardiovascular- and cancer-related morbidities during cross-sex hormone therapy in the patients being treated at our center since 1986 .

\section{Subject and methods}

\section{Study population and study procedures}

All persons diagnosed with GID (Diagnostic and Statistical Manual of Mental Disorders-III-R and DSM-IV, 302.85; International Classification of Diseases, 10th revision, F64.0) at the Center for Sexology and Gender Problems at the Ghent University Hospital (Ghent, Belgium) between 1986 and June 2012 and who underwent at least 3 months of cross-sex hormone therapy were invited by letter to participate in this study. The respondents were sent a paper version of the questionnaire by post or they filled out the survey online. A reminder message was sent to the nonresponders. All surveys were collected between August and December 2012. We achieved a response rate of $54 \%$ as 352 participants, including 214 trans women and 138 trans men, agreed to participate in this study (Fig. 1). Ten of the invited persons died during the follow-up period.

Ten trans women were no longer on estrogen therapy due to previous thromboembolic events $(n=5)$, dissatisfaction $(n=2)$, or other reasons $(n=3)$. The remaining trans women were on hormone therapy for an average of 7.7 years (range: 3 months-35 years) (Fig. 2). In trans women, current cross-sex hormone

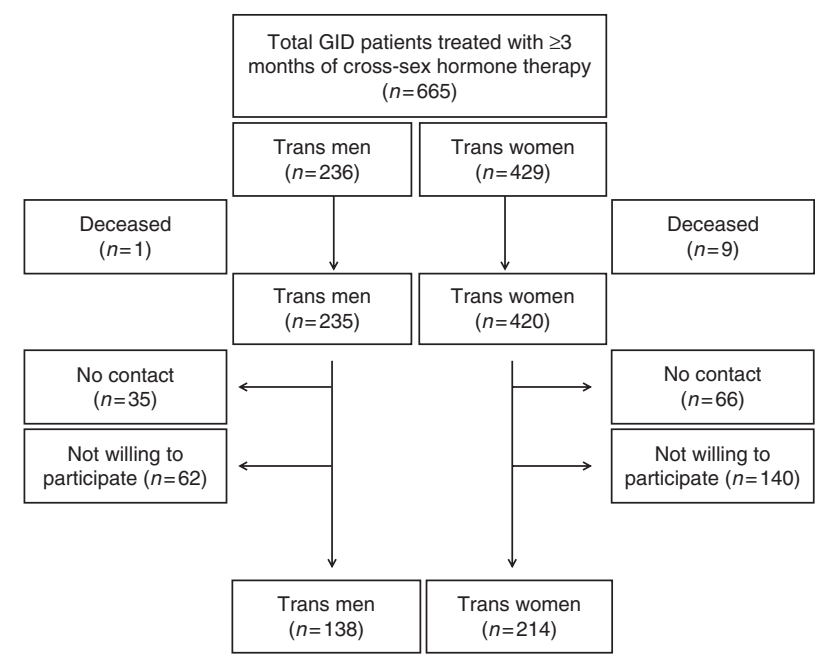

Figure 1 Subject enrollment.

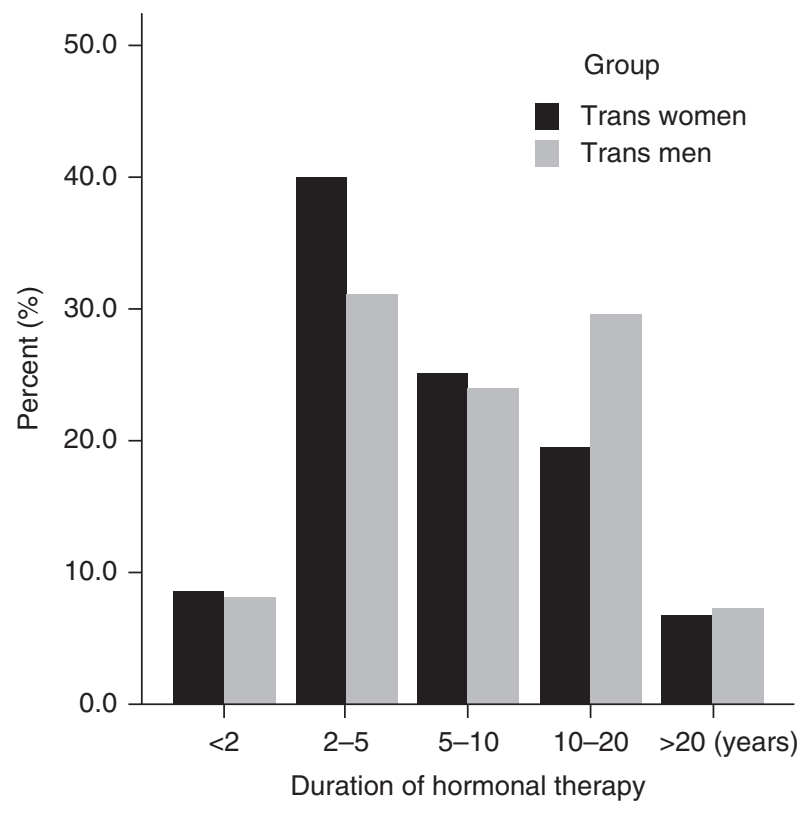

Figure 2 Duration of hormone therapy in trans persons.

therapy consisted of transdermal estradiol $(1.5 \mathrm{mg} / 24 \mathrm{u}$ $17 \beta$-estradiol gel $(n=76 ; 35.5 \%) ; 50 \mu \mathrm{g} / 24 \mathrm{u}$ estradiol patch $(n=29 ; 13.6 \%)$; or daily intake of oral estrogens, $2 \mathrm{mg}$ estradiol valerate $(n=91 ; 42.5 \%), 2 \mathrm{mg}$ estriol $(n=1 ; 0.4 \%), 50 \mu \mathrm{g}$ ethinyl estradiol $(n=2 ; 0.9 \%)$, and 30-50 $\mu \mathrm{g}$ ethinyl estradiol oral contraceptive $(n=5$; $2.3 \%)$. A majority of the trans women $(n=129 ; 65 \%)$ in this study underwent orchiectomy.

Trans men were on testosterone replacement therapy for an average of 9.4 years (range: 3 months -49 years). Cross-sex hormone therapy in trans men consisted of intramuscular testosterone treatment with either a mixture of testosterone esters (testosterone decanoate $100 \mathrm{mg}$, testosterone isocaproate $60 \mathrm{mg}$, testosterone phenylpropionate $60 \mathrm{mg}$, and testosterone propionate $30 \mathrm{mg} / \mathrm{ml})$ every 2 or 3 weeks $(n=64 ; 46.4 \%)$; testosterone undecanoate $1000 \mathrm{mg}$ for 12 weeks $(n=62 ; 44.9 \%)$; transdermal testosterone $50 \mathrm{mg}$ daily $(n=9 ; 6.5 \%)$; or oral testosterone undecanoate $(n=2$; $1.4 \%)$. Eighty-six percent of trans men $(n=118)$ underwent hysterectomy/ovariectomy.

The participants were questioned about their physical health, incidence of possible treatment-related adverse events, sociodemographic status, healthrelated quality of life (QoL), treatment-related symptoms, surgical results, and satisfaction with hormonal and surgical treatment. Data concerning QoL, treatment satisfaction, and sexual desire have been reported elsewhere (K Wierckx, E Elaut, J Motmans, G Heylens, G De Cuypere, E Anseeuw, L Geerts \& G T'Sjoen, unpublished observations; K Wierckx, E Elaut, G Heylens, G De Cuypere, B Van Hoorde, S Monstrey, S Weyers, P Hoebeke \& G T'Sjoen, unpublished observations). 
For both trans men and women, age-matched female and male control groups were used to compare data concerning cardiovascular disease- and cancer-related morbidities. We focused on relatively common morbidities in the general population to obtain accurate estimates of their prevalence. We also studied morbidities that could be assessed reliably using a questionnaire.

The control group for trans women consisted of 619 women and 640 men, and the control group for trans men consisted of 414 women and 414 men. This control group was randomly selected (three control men and three control women for each subject) and was recruited from a population-based study in Flanders. The methods used for this study have been described elsewhere (16). Briefly, the control population was recruited from a survey of sexual health characteristics and biomedical, psychological, demographic, and sociocultural correlates in persons aged between 14 and 80 years. Data were collected on 1832 respondents (response rate: $40.0 \%$ of the eligible respondents) between February 2011 and January 2012. The respondents were randomly drawn from the Belgian National Register. All data were gathered via faceto-face interviews using a combination of computerassisted personal interviewing and computer-assisted self-interviewing. Both studies were approved by the ethical review board of Ghent University Hospital, Belgium. All the participants gave their consent to participate in the study.

\section{Main outcome measures}

Physical health and incidence of possible treatment-related adverse events Medical history, medication use, smoking habits, weight, height, current and past hormone treatment, and clinical adverse events (e.g., acute myocardial infarction, venous thrombosis and/or pulmonary embolism, type 2 diabetes, transient ischemic attack (TIA), stroke, and cancer) were addressed using a questionnaire that we developed. Morbidity data before the start of hormone therapy were retrieved from medical files. Medical information was corrected from medical files.

\section{Statistical analysis}

Descriptives are expressed as mean and S.D. or median (first to third quartiles) when criteria for normal distribution are not fulfilled. Linear regression analyses were used to compare linear variables between the groups with group being the independent variable. Dichotomous and categorical variables were analyzed using logistic regression and $\chi^{2}$ tests respectively.

Table 1 General characteristics of trans women and their control group. Data are presented as mean (s.D.) or median (first to third quartiles) in case of non-Gaussian distribution. Categorical variables were analyzed using $\chi^{2}$ test; linear variables were analyzed using ANOVA.

\begin{tabular}{|c|c|c|c|c|c|}
\hline & $\begin{array}{l}\text { Trans women } \\
\quad(n=214)\end{array}$ & $\begin{array}{l}\text { Control men } \\
(n=640)\end{array}$ & $\begin{array}{l}\text { Control women } \\
\quad(n=619)\end{array}$ & $\boldsymbol{P}$ men & $P$ women \\
\hline $\begin{array}{l}\text { Age at the time of study (years) } \\
\text { In a relationship currently (\%) }\end{array}$ & $\begin{array}{l}43.7 \pm 12.6 \\
47.2\end{array}$ & $\begin{array}{l}43.4 \pm 13.7 \\
82.7\end{array}$ & $\begin{array}{l}43.1 \pm 13.1 \\
83.9\end{array}$ & $\begin{array}{l}\text { NS } \\
<0.001\end{array}$ & $\begin{array}{l}\text { NS } \\
<0.001\end{array}$ \\
\hline \multicolumn{6}{|l|}{ Work status (\%) } \\
\hline Unemployed & 14.2 & 1.8 & 7.2 & $<0.001$ & $<0.001$ \\
\hline Employed & 55.9 & 77.2 & 70.8 & & \\
\hline Retired & 9.5 & 10.3 & 6.2 & & \\
\hline Student & 5.2 & 9.0 & 8.4 & & \\
\hline Unable to work & 13.7 & 1.7 & 4.3 & & \\
\hline Household & 1.4 & 0 & 7.4 & & \\
\hline \multicolumn{6}{|l|}{ Income (\%) } \\
\hline$\leq 999 €$ & 10.3 & 0.2 & 2.9 & $<0.001$ & $<0.001$ \\
\hline $1.000-1.999 €$ & 42.2 & 16.6 & 20.9 & & \\
\hline $2.000-2.999 €$ & 27.5 & 29.0 & 28.5 & & \\
\hline $3.000-5.999 €$ & 16.7 & 49.2 & 44.8 & & \\
\hline$\geq 6.000 €$ & 3.4 & 5.1 & 2.9 & & \\
\hline \multicolumn{6}{|l|}{ Educational level } \\
\hline Primary & 6.3 & 3.5 & 5.7 & NS & NS \\
\hline Lower secondary & 19.2 & 20.6 & 17.4 & & \\
\hline Higher secondary & 31.3 & 38.9 & 28.8 & & \\
\hline Bachelor & 26.4 & 28.7 & 43.9 & & \\
\hline Master & 12.5 & 1.3 & 1.1 & & \\
\hline Master after master & 4.3 & 7.0 & 3.2 & & \\
\hline $\operatorname{BMI}\left(\mathrm{kg} / \mathrm{m}^{2}\right)$ & $24.4(21.7-27.9)$ & $24.8(22.7-27.4)$ & $23.5(21.2-26.5)$ & 0.07 & NS \\
\hline SRS (\%) & 64.8 & - & - & - & - \\
\hline Time since SRS (years) & $6.0(2-11)$ & - & - & - & - \\
\hline Duration of hormone therapy (years) & $6.0(3-11)$ & _- & _ & _ & _ \\
\hline Use of sex steroid therapy (\%) & 95.3 & 0.3 & 29.1 & $<0.001$ & $<0.001$ \\
\hline
\end{tabular}

NS, not significant; SRS, sex reassignment surgery. 
Table 2 General characteristics of trans men and their control group. Data are presented as mean (s.D.) or median (first to third quartiles) in case of non-Gaussian distribution. Categorical variables were analyzed using $\chi^{2}$ test; linear variables were analyzed using ANOVA.

\begin{tabular}{|c|c|c|c|c|c|}
\hline & $\begin{array}{c}\text { Trans men } \\
(n=138)\end{array}$ & $\begin{array}{c}\text { Control men } \\
(n=414)\end{array}$ & $\begin{array}{c}\text { Control women } \\
(n=414)\end{array}$ & $P$ men & $P$ women \\
\hline Age at the time of study (years) & $37.5 \pm 11.0$ & $37.1 \pm 11.9$ & $37.4 \pm 10.1$ & NS & NS \\
\hline In a relationship currently (\%) & 62.3 & 77.3 & 82.6 & $<0.001$ & $<0.001$ \\
\hline Children (\%) & 23.9 & 44.1 & 58.1 & $<0.001$ & $<0.001$ \\
\hline \multicolumn{6}{|l|}{ Work status (\%) } \\
\hline Unemployed & 9.4 & 1.3 & 4.2 & 0.001 & 0.02 \\
\hline Employed & 64.5 & 77.2 & 69.6 & & \\
\hline Retired & 1.5 & 2.3 & 2.0 & & \\
\hline Student & 13.0 & 18.2 & 16.5 & & \\
\hline Unable to work & 9.4 & 1.0 & 3.7 & & \\
\hline Household & 2.2 & 0 & 4.0 & & \\
\hline \multicolumn{6}{|l|}{ Income (\%) } \\
\hline$\leq 999 €$ & 14.2 & 0 & 1.5 & $<0.001$ & $<0.001$ \\
\hline $1.000-1.999 €$ & 35.8 & 14.0 & 18.1 & & \\
\hline $2.000-2.999 €$ & 24.6 & 28.3 & 25.1 & & \\
\hline $3.000-5.999 €$ & 23.9 & 52.6 & 52.6 & & \\
\hline$\geq 6.000 €$ & 1.5 & 5.1 & 2.6 & & \\
\hline \multicolumn{6}{|l|}{ Educational level } \\
\hline Primary & 8.8 & 2.0 & 3.3 & NS & NS \\
\hline Lower secondary & 11.7 & 18.9 & 13.4 & & \\
\hline Higher secondary & 36.5 & 41.8 & 31.8 & & \\
\hline Bachelor degree & 25.5 & 30.6 & 46.2 & & \\
\hline Master & 12.4 & 0.7 & 1.0 & & \\
\hline Master after master & 5.1 & 6.1 & 4.3 & & \\
\hline BMI $\left(\mathrm{kg} / \mathrm{m}^{2}\right)$ & $24.3(22.2-27.5)$ & $23.1(20.9-26.2)$ & $24.2(22.2-26.6)$ & NS & 0.02 \\
\hline SRS (\%) & 85.5 & - & - & & \\
\hline Time since SRS (years) & $7.0(4-13)$ & - & - & - & - \\
\hline Duration of hormone therapy (years) & $7.0(4-13)$ & - & - & - & - \\
\hline Use of sex steroid therapy (\%) & 100 & 0.2 & 36.2 & $<0.001$ & $<0.001$ \\
\hline
\end{tabular}

NS, not significant; SRS, sex reassignment surgery.

Morbidity comparisons between the groups were adjusted for age. Data were analyzed using the PASW software, v.19 (SPSS, Inc.). Statistical significance was set at $P<0.05$, and all tests were two-tailed.

\section{Results}

\section{General characteristics}

General characteristics of the study population are described in Tables 1 and 2.
Almost 30\% $(n=179)$ of women in the control group of the trans women used sex steroid medication, including oral contraceptives $(n=93 ; 15 \%)$, hormonal coil $(n=33 ; 5.9 \%)$, hormone replacement therapy $(n=21 ; 34 \%)$, vaginal ring $(n=14 ; 2.3 \%)$, or others $(n=17 ; 2.8 \%)$. One man in the control group of the trans women used oral testosterone undecanoate and another used intramuscular testosterone esters.

In the control group of the trans men, $36.2 \%$ $(n=150)$ of women used sex steroid medication, including oral contraceptives $(n=89 ; 21.5 \%)$, hormonal coil $(n=34 ; 8.2 \%)$, hormone replacement therapy

Table 3 Prevalence of morbidity in trans women compared with an age-matched control population. Data are presented as cases/1000 persons; logistic regression was adjusted for age.

\begin{tabular}{lcccccc}
\hline & $\begin{array}{c}\text { Trans women } \\
\text { before HRT }\end{array}$ & $\begin{array}{c}\text { Trans } \\
\text { women }\end{array}$ & $\begin{array}{c}\text { Age-matched } \\
\text { control men }\end{array}$ & $\begin{array}{c}\text { Age-matched } \\
\text { control women }\end{array}$ & $\boldsymbol{P}$ men & $\boldsymbol{P}$ women \\
\hline VT and/or PE & 9.2 & 60.7 & - & - & - & - \\
Myocardial infarction & 4.7 & 18.7 & 12.5 & 0 & $\mathrm{NS}$ & 0.001 \\
TIA/CVD & 4.7 & 23.4 & 9.4 & 14.9 & 0.03 & $\mathrm{NS}$ \\
Obesity & 56.0 & 116.8 & 92.0 & 107.6 & $\mathrm{NS}$ & $\mathrm{NS}$ \\
Type 2 diabetes mellitus & 37.3 & 42.0 & 6.2 & 14.9 & 0.04 & 0.021 \\
Cancer & 18.7 & 28.0 & 21.9 & 24.9 & $\mathrm{NS}$ & $\mathrm{NS}$ \\
\hline
\end{tabular}

NS, not significant; VT, venous thrombosis; PE, pulmonary embolism; TIA, transient ischemic attack; CVD, cerebrovascular disease.

${ }^{\text {a }}$ Retrieved from patient files. 
Table 4 Prevalence of cardiovascular disease and cancer morbidities in trans men compared with an age-matched control population. Data are presented as cases/1000 persons; logistic regression was adjusted for age.

\begin{tabular}{|c|c|c|c|c|c|c|}
\hline & $\begin{array}{c}\text { Trans men } \\
\text { before } \text { HRT }^{a}\end{array}$ & $\begin{array}{l}\text { Trans } \\
\text { men }\end{array}$ & $\begin{array}{l}\text { Control } \\
\text { men }\end{array}$ & $\begin{array}{l}\text { Control } \\
\text { women }\end{array}$ & $\boldsymbol{P}$ men & $\boldsymbol{P}$ women \\
\hline VT and/or PE & 14.5 & 14.5 & - & - & - & - \\
\hline Myocardial infarction & 0 & 0 & 7.3 & 0 & NS & NS \\
\hline TIA/CVD & 0 & 0 & 7.3 & 7.3 & NS & NS \\
\hline Obesity & 79.7 & 137.7 & 92.0 & 118.6 & NS & NS \\
\hline Type 2 diabetes mellitus & 14.5 & 36.2 & 7.3 & 0 & 0.06 & $<0.001$ \\
\hline
\end{tabular}

NS, not significant; VT, venous thrombosis; PE, pulmonary embolism; TIA, transient ischemic attack; CVD, cerebrovascular disease.

${ }^{\text {a }}$ Retrieved from patient files.

$(n=8 ; 1.9 \%)$, vaginal ring $(n=9 ; 2.2 \%)$, or others $(n=10 ; 2.4 \%)$. One man in this control group used intramuscular testosterone esters.

\section{Morbidity in trans persons compared with the control population}

Cardiovascular disease- and cancer-related morbidities in trans women and men and their respective control groups are given in Tables 3 and 4 respectively.

Eleven trans women $(5.1 \%)$ experienced venous thrombosis and/or pulmonary embolism during hormone therapy. Almost half of these incidents occurred during the first year of treatment $(n=5)$, another three at the time of sex reassignment surgery (SRS), one after 3 years of hormone therapy, another after 11 years, and one after 22 years of hormone therapy. In all but one incident, one or more of the following risk factors were present: smoking $(n=7)$, immobilization $(n=3)$, and/or clotting disorder $(n=1)$. Hormone treatment at the time of the incident consisted of $50 \mathrm{mg}$ cyproterone acetate $(n=2), 4 \mathrm{mg}$ estradiol valerate in combination with $50 \mathrm{mg}$ cyproterone acetate $(n=2), 4 \mathrm{mg}$ estradiol valerate $(n=1), 2 \mathrm{mg}$ transdermal $17 \beta$-estradiol $(n=3)$, $50 \mu \mathrm{g}$ ethinyl estradiol $(n=1), 0.625 \mathrm{mg}$ conjugated equine estrogens $(n=1)$, or unknown $(n=1)$.

Three cases of acute myocardial infarction were diagnosed within the first 2 years of combined antiandrogen and estrogen treatment. The patients were 48 years of age, on average, at the time of the event (Table 5).

TIA or cerebrovascular disease (CVD) was diagnosed in five trans women after an average of 7.2 years of hormone therapy (range 2-20). The patients were 51 years of age, on average, at the time of the event (Table 5).

The BMI of trans women was similar to that of the control men and women (data not shown). The BMI of trans men was similar to that of the control men, but it was higher than that of the control women $(P=0.02)$. The prevalence of obesity in trans women and men was similar to that in the control population. The prevalence of cancer in trans persons was similar or lower to that in the control men and women. Three cases of colon carcinoma, two cases of melanoma, and one case of lymphoma were diagnosed in trans women. None of the trans men experienced cancer during the follow-up period.

\section{Mortality in trans persons}

Ten trans persons (one trans man and nine trans women) died during the follow-up period. The causes of death were suicide $(n=6)$, cardiovascular disease $(n=2)$, cancer $(n=1)$, and unknown $(n=1)$. Three patients committed suicide during hormone therapy and before SRS, while three committed suicide after SRS.

\section{Discussion}

This study presents follow-up data related to cardiovascular disease- and cancer-related morbidities during

Table 5 Description of cardiovascular events in trans women.

\begin{tabular}{|c|c|c|c|}
\hline & $\begin{array}{c}\text { Age at } \\
\text { event } \\
\text { (years) }\end{array}$ & $\begin{array}{c}\text { Duration } \\
\text { of HRT } \\
\text { (years) }\end{array}$ & $\begin{array}{l}\text { Cardiovascular } \\
\text { risk factors }\end{array}$ \\
\hline \multicolumn{4}{|c|}{ Venous thrombosis and/or pulmonary embolism } \\
\hline Case 1 & 33 & 1 & Smoker \\
\hline Case 2 & 28 & 1 & $\mathrm{HC}$ \\
\hline Case 3 & 54 & 1 & Smoker \\
\hline Case 4 & 53 & 22 & Smoker, $\mathrm{HC}$, and $\mathrm{HT}$ \\
\hline Case 5 & 54 & 1 & $\begin{array}{l}\text { Smoker, HC, and clotting } \\
\text { disorder }\end{array}$ \\
\hline Case 6 & 38 & 2 & Smoker, $\mathrm{HC}$, and surgery \\
\hline Case 7 & 32 & 1 & Smoker \\
\hline Case 8 & 50 & 3 & Smoker and $\mathrm{HT}$ \\
\hline Case 9 & 32 & 2 & $\mathrm{HC}$ and surgery \\
\hline Case 10 & 44 & 2 & Surgery \\
\hline Case 11 & 58 & 11 & $\mathrm{HC}$ \\
\hline \multicolumn{4}{|c|}{ Myocardial infarction } \\
\hline Case 1 & 52 & 1 & Smoker and $\mathrm{HC}$ \\
\hline Case 2 & 50 & 1 & Former smoker \\
\hline Case 3 & 42 & 2 & Smoker, $\mathrm{HC}$, and $\mathrm{HT}$ \\
\hline \multicolumn{4}{|l|}{ TIA/CVD } \\
\hline Case 1 & 33 & 2 & Smoker, $\mathrm{HC}$, and surgery \\
\hline Case 2 & 53 & 2 & $\begin{array}{l}\text { Smoker, } \mathrm{HC}, \mathrm{HT} \text {, and } \\
\text { type } 2 \text { diabetes mellitus }\end{array}$ \\
\hline Case 3 & 56 & 10 & $\begin{array}{l}\mathrm{HT} \text { and mechanic heart } \\
\text { valve }\end{array}$ \\
\hline Case 4 & 58 & 20 & Smoker and $\mathrm{HC}$ \\
\hline Case 5 & 56 & 2 & Smoker \\
\hline
\end{tabular}

$\mathrm{HC}$, hypercholesterolemia; HT, hypertension. 
short- and long-term cross-sex hormone therapy administration in a large group of trans persons. Similar to others $(7,9)$, we observed a relatively high risk of venous thrombosis and/or pulmonary embolism during cross-sex hormone therapy in trans women. The incidence of venous thrombosis and/or pulmonary embolism in this study $(5.1 \%)$ was lower than that reported by Van Kesteren et al. (7), who showed that $6.4 \%$ of their sample experienced this during hormone treatment. The use of high-dose oral ethinyl estradiol (100 $\mu \mathrm{g}$ OD) may explain the higher incidence in the latter study, as the type and route of administration of this estrogen are known to affect the coagulation system negatively $(5,17,18)$. However, Ott et al. (19) did not observe any venous thrombosis and/or pulmonary embolism incidents during their follow-up study of 162 trans women (mean age 36 years) who received transdermal $17 \beta$-estradiol therapy for an average of 4.4 years. This may be a safer type of estrogen and route of administration, although $37 \%$ of the trans women who experienced venous thromboses in our sample received transdermal $17 \beta$-estradiol therapy. The older age of the participants and the longer follow-up period in the present study may also contribute to the higher incidence of these events.

The increased risk of CVD in trans women compared with the control men corroborates with the findings of our previous follow-up study (6) and with those of the study of Asscheman et al. (5). The latter found a higher mortality rate due to CVD in trans women aged between 40 and 64 years. Oral contraceptive use and hormone replacement therapy have been reported to be associated with an increased risk of $\operatorname{CVD}(20,21)$, and our results suggest that this may also be true for cross-sex hormone therapy in trans women.

We also showed that trans women had a higher prevalence of myocardial infarction than the control women, but had a prevalence similar to that exhibited by the control men. Asscheman et al. (5) also observed that long-term hormone replacement therapy does not decrease the risk of coronary events in trans women compared with community-dwelling men. It may be that these results represent the pre-existing gender differences in coronary events (22), as a considerable part of this discrepancy in cardiovascular health cannot be explained by lifestyle or other cardiovascular risk factors. Moreover, in our previous follow-up study, we had observed that aside from a higher smoking rate, trans persons had a similar number or fewer cardiovascular risk factors compared with the general population (6). Another explanation may be that similar to the timing hypothesis in postmenopausal women $(23,24)$, estrogen therapy effects in trans women may depend on the individual's cardiovascular health at the start of the therapy. Estrogen therapy can aggravate pre-existing cardiovascular disease in older trans women, whereas it may exert beneficial cardiovascular effects in young and healthy trans women. Our results may support this hypothesis, as the majority of trans women who experienced myocardial infarction or CVD were aged over 50 years, had one or more cardiovascular risk factors (mainly smoking), and had undergone cross-sex hormone therapy for a short duration. Although cardiovascular risk factors should be managed in trans women (3), current guidelines do not specify at what age and how patients with cardiovascular risk factors should be treated. Based on these preliminary results, we recommend that older trans women with well-known cardiovascular risk factors, especially smoking, should be closely monitored, in particular, at the start of cross-sex hormone treatment. Furthermore, cardiovascular risk factors including hypertension, hypercholesterolemia, and smoking should be managed before initiating cross-sex hormone therapy in trans women at a risk of cardiovascular disease. Further research is needed to investigate possible mechanisms contributing to increased cardiovascular disease risk during cross-sex hormone treatment, as well as the safety of different cross-sex hormone therapies in older trans women.

Similar to others $(7,8,9)$, we found that testosterone treatment in trans men was relatively safe in relation to short- and medium-term cardiovascular health. However, risks may become more apparent as subjects grow older and the duration of hormone exposure increases $(10,25)$.

To our knowledge, previous morbidity studies $(7,9)$ have not investigated the prevalence of type 2 diabetes in trans persons compared with the control individuals. We discovered that both trans men and women had a higher prevalence of type 2 diabetes than the control men and women, with almost all diagnoses being made before starting hormone therapy in trans women. Because trans persons are carefully screened by endocrinologists before hormone therapy, the presence of type 2 diabetes may be diagnosed more frequently. The incidence of type 2 diabetes during hormone therapy was also higher in trans men than in the control men and women, although the overall number of cases that we observed was relatively low. Hyperandrogenism in biological women has been reported to be associated with increased insulin resistance due to direct effects on skeletal muscle and adipose tissue insulin action $(26,27)$, altered adipokine secretion, and increased visceral adiposity (28). Furthermore, one study investigating the effects of androgen administration on insulin sensitivity, evaluated by euglycemic clamp (29), has observed that testosterone treatment significantly decreases insulin-mediated glucose disposal in trans men, although another study from the same group (30) was unable to reproduce these findings. Trans men also had a higher BMI than the control women. This suggests that lifestyle differences between the groups may contribute to this discrepancy, although the prevalence of obesity was not different between the trans men and control women. 
We observed no difference in the prevalence of cancer between trans persons and the control population, which is in line with the results reported by Asscheman et al. (5). However, Dhejne et al. (4) found that the cause-specific risk of death from neoplasms in trans persons was double that in control individuals, although this was unlikely to be related to cross-sex hormone treatment. Although the incidence of hormone-related cancers was not higher in the trans groups at either short- or medium-term follow-up, the incidence of hormone-related cancers may increase with longer duration of hormone treatment (10).

Trans women had a higher mortality rate than trans men, although the number of mortalities was relatively small. Similar to others $(5,7)$, we found that the prevalence of suicide in trans persons $(902 / 100000$ persons) was higher than that in the general Belgian female (12.8/100 000 persons) and male (34.9/ 100000 persons) populations within the same age category, especially in trans women (31). Even though cross-sex reassignment therapy has been reported to be associated with better functioning in terms of gender dysphoria relief, QoL improvement, psychological functioning, and decrease in suicide attempts $(32,33$, $34,35,36)$, the relatively high suicide rate during and after transition shows the fragile psychological position of some trans persons.

The main limitation of this study is the possible selection bias, as we had a modest response rate of $54 \%$. Furthermore, the relatively small sample size prevented us from determining the accurate prevalence of morbidity and mortality. Combining databases from other specialized centers may help solve these problems and improve the safety and clinical care related to crosssex hormone therapy. Additionally, because many of the women in the control groups used hormone therapy, we may have underestimated the observed differences in morbidity rates in trans persons and the control population. However, because the control population was randomly drawn from the national register, we assume that a representative population sample was used in our analysis.

In conclusion, the data of this study indicate relatively low morbidity rates during cross-sex hormone therapy, especially in trans men. We observed a higher cardiovascular morbidity rate in trans women than in the female and male controls.

\section{Declaration of interest}

The authors declare that there is no conflict of interest that could be perceived as prejudicing the impartiality of the research reported.

\section{Funding}

K Wierckx was supported by the Special research Funds of Ghent University, grant number 01D20711.

\section{Acknowledgements}

The authors are indebted to Robert Rubens, MD, PhD; Steven Weyers, $\mathrm{MD}, \mathrm{PhD}$; Piet Hoebeke, MD, PhD; and Stan Monstrey, MD, PhD, for the referral of patients and to Kaatje Toye, Lieselot Geerts, and Edward Anseeuw for their help and assistance in the study. The authors also thank the respondents who participated in this study for their time and cooperation.

\section{References}

1 Bockting W, Botzer M, Cohen-Kettenis P, De Cuypere G, Feldman J, Fraser L, Green J, Knudson G, Meyer WJ, Monstrey S et al., Standards of Care for the Health of Transsexual, Transgender, and Gender Nonconforming People. International Journal of Transgenderism 201113 165-232.

2 Gooren LJ, Giltay EJ \& Bunck MC. Long-term treatment of transsexuals with cross-sex hormones: extensive personal experience. Journal of Clinical Endocrinology and Metabolism 200893 19-25. (doi:10.1210/jc.2007-1809)

3 Hembree WC, Cohen-Kettenis P, Delemarre-van de Waal HA, Gooren LJ, Meyer WJ, Tangpricha V \& Montori VM. Endocrine treatment of transsexual persons: an Endocrine Society clinical practice guideline. Journal of Clinical Endocrinology and Metabolism 200994 3132-3154. (doi:10.1210/jc.2009-0345)

4 Dhejne C, Lichtenstein P, Boman M, Johansson A, Langström N \& Landén M. Long-term follow-up of transsexuals' persons undergoing sex reassignment surgery: cohort study in Sweden. PLOS ONE 20116 e16885. (doi:10.1371/journal.pone.0016885)

5 Asscheman H, Giltay EJ, Megens J, de Ronde W \& Trotsenburg MA. A long term follow-up study of mortality in transsexuals receiving treatment with cross-sex hormones. European Journal of Endocrinology 2011164 635-642. (doi:10.1530/EJE-10-1038)

6 Wierckx K, Mueller S, Weyers S, Van Caenegem E, Roef G, Heylens G \& T'Sjoen G. A long-term evaluation of cross-sex hormone treatment in transsexual persons. Journal of Sexual Medicine 20129 2641-2651. (doi:10.1111/j.1743-6109.2012. 02876.x)

7 Van Kesteren PJ, Asscheman H, Megens JA \& Gooren LJ. Mortality and morbidity in transsexual subjects treated with cross-sex hormones. Clinical Endocrinology 1997 47 337-342. (doi:10.1046/j.1365-2265.1997.2601068.x)

8 Bazarra-Castro MA, Sievers C, Fulda S, Klotsche J, Pieper L \& Wittchen H é Stalla GK. Co morbidities in transsexual patients under hormone treatment compared to age- and gender-matched primary care comparison groups. Reproductive System \& Sexual Disorders 20121 1. (doi:10.4172/2161-038X.1000101)

9 Asscheman H, Gooren LJG \& Eklund PL. Mortality and morbidity in transsexual patients with cross-gender treatment. Metabolism 198938 869-873. (doi:10.1016/0026-0495(89)90233-3)

10 Traish AM \& Gooren LJ. Safety of physiological testosterone therapy in women: lessons from female-to-male transsexuals (FMT) treated with pharmacological testosterone therapy. Journal of Sexual Medicine 20107 3758-3764. (doi:10.1111/ j.1743-6109.2010.01962.x)

11 Scarabin PY, Oger E \& Plu-Bureau G. Differential association of oral and transdermal oestrogen-replacement therapy with venous thromboembolism risk. Lancet $2003 \quad 362$ 428-432. (doi:10.1016/S0140-6736(03)14066-4)

12 Lidegaard, Løkkegaard E, Jensen A, Skovlund CW \& Keiding N. Thrombotic stroke and myocardial infarction with hormonal contraception. New England Journal of Medicine $2012 \mathbf{3 6 6}$ 2257-2266. (doi:10.1056/NEJMoa1111840)

13 Lidegaard Ø, Løkkegaard E, Svendsen AL \& Agger C. Hormonal contraception and risk of venous thromboembolism: national follow-up study. BMJ 20093392890 . (doi:10.1136/bmj.b2890)

14 Mueller A \& Gooren L. Hormone-related tumors in transsexuals receiving treatment with cross-sex hormones. European Journal of Endocrinology 2008159 197-202. (doi:10.1530/EJE-08-0289) 
15 Gooren L. Care of transsexual persons. New England Journal of Medicine 2011364 1251-1257. (doi:10.1056/NEJMcp 1008161)

16 Buysse A, Caen M, Dewaele A, Enzlin P, Lievens J, T'Sjoen G,Van Houtte M \& Vermeersch H. Seksuele gezondheid in Vlaanderen [Sexual health in Flanders] 2013, Gent: Academia Press.

17 Toorians AW, Thomassen MC, Zweegman S, Magdeleyns EJ, Tans G, Gooren LJ \& Rosing J. Venous thrombosis and changes of hemostatic variables during cross-sex hormone treatment in transsexual people. Journal of Clinical Endocrinology and Metabolism 200388 5723-5729. (doi:10.1210/jc.2003-030520)

18 Laliberté F, Dea K, Duh M, Kahler K, Rolli M \& Lefebvre P. Does the route of administration for estrogen hormone therapy impact the risk of venous thromboembolism? Estradiol transdermal system versus oral estrogen-only hormone therapy. Menopause $2011 \mathbf{1 8}$ 1052-1059. (doi:10.1097/gme.0b013e3182175e 5c)

19 Ott J, Kaufmann U, Bentz EK, Huber JC \& Tempfer CB. Incidence of thrombophilia and venous thrombosis in transsexuals under cross-sex hormone therapy. Fertility and Sterility 201093 1267-1272. (doi:10.1016/j.fertnstert.2008.12.017)

20 Kemmeren J, Tanis B, van den Bosch M, Bollen E, Helmerhorst F, van der Graaf Y, Rosendaal F \& Algra A. Risk of Arterial Thrombosis in Relation to Oral Contraceptives (RATIO) study: oral contraceptives and the risk of ischemic stroke. Stroke 200233 1202-1208. (doi:10.1161/01.STR.0000015345.61324.3F)

21 Sare G, Gray L \& Bath P. Association between hormone replacement therapy and subsequent arterial and venous vascular events: a meta-analysis. European Heart Journal 2008 29 2031-2041. (doi:10.1093/eurheartj/ehn299)

22 Jousilahti P, Vartiainen E, Tuomilehto J \& Puska P. Sex, age, cardiovascular risk factors, and coronary heart disease: a prospective follow-up study of 14786 middle-aged men and women in Finland. Circulation 199999 1165-1172. (doi:10.1161/01.CIR. 99.9.1165)

23 Hsia J, Langer RD, Manson JE, Kuller L, Johnson KC, Hendrix SL, Pettinger M, Heckbert SR, Greep N, Crawford S et al. Conjugated equine estrogens and coronary heart disease: the Women's Health Initiative. Archives of Internal Medicine 2006166 357-365. (doi:10.1001/archinte.166.3.357)

24 Salpeter SR, Walsh JM, Greyber E \& Salpeter EE. Brief report: coronary heart disease events associated with hormone therapy in younger and older women. A meta-analysis. Journal of General Internal Medicine 200621 363-366. (doi:10.1111/j.1525-1497. 2006.00389.x)

25 Gooren LJ \& Giltay EJ. Review of studies of androgen treatment of female-to-male transsexuals: effects and risks of administration of androgens to females. Journal of Sexual Medicine 2008 5 765-776. (doi:10.1111/j.1743-6109.2007.00646.x)

26 Allemand MC, Irving BA, Asmann YW, Klaus KA, Tatpati L, Coddington CC \& Nair KS. Effect of testosterone on insulin stimulated IRS-1 Ser phosphorylation in primary rat myotubes - a potential model for PCOS-related insulin resistance. PLOS ONE 20094 e4274. (doi:10.1371/journal.pone.0004274)
27 Corbould A. Chronic testosterone treatment induces selective insulin resistance in subcutaneous adipocytes of women. Journal of Endocrinology 2007192 585-594. (doi:10.1677/joe.1.07070)

28 Lovejoy JC, Bray GA, Bourgeois MO, Macchiavelli R, Rood JC, Greeson C \& Partington C. Exogenous androgens influence body composition and regional body fat distribution in obese postmenopausal women - a clinical research center study. Journal of Clinical Endocrinology and Metabolism 199681 2198-2203. (doi:10.1210/jc.81.6.2198)

29 Polderman KH, Gooren LJG, Asscheman H, Bakker A \& Heine RJ. Induction of insulin resistance by androgens and estrogens. Journal of Clinical Endocrinology and Metabolism 199479 265-271. (doi:10.1210/jc.79.1.265)

30 Elbers JM, Giltay EJ, Teerlink T, Scheffer PG, Asscheman H, Seidell JC \& Gooren LJ. Effects of sex steroids on components of the insulin resistance syndrome in transsexual subjects. Clinical Endocrinology $2003 \mathbf{5 8}$ 562-571. (doi:10.1046/j.1365-2265. 2003.01753.x)

31 Sterftecertificaten alle overlijdens, Vlaams Gewest, 2010. Team Gegevensverwerking en Resultaatsopvolging. Zelfdoding per leetijd [Online publicatie]. Brussel: Vlaams Agentschap Zorg en Gezondheid, Afd. Informatie en Ondersteuning, [geraadpleegd op 11-08-2013], available on: http://www.zorg-en-gezondheid.be/ Cijfers/Sterftecijfers/Cijfers-oorzaken-van-sterfte/Zelfdoding-perleeftijd/\#leeftijd

32 Murad MH, Elamin MB, Garcia MZ, Mullan RJ, Murad A, Erwin PJ \& Montori VM. Hormonal therapy and sex reassignment: a systematic review and meta-analysis of quality of life and psychosocial outcomes. Clinical Endocrinology 2010 72 214-231. (doi:10.1111/j.1365-2265.2009.03625.x)

33 Newfield E, Hart S, Dibble S \& Kohler L. Female-to-male transgender quality of life. Quality of Life Research 200615 1447-1457. (doi:10.1007/s11136-006-0002-3)

34 Lawrence AA. Patient-reported complications and functional outcomes of male-to-female sex reassignment surgery. Archives of Sexual Behavior 200635 717-727. (doi:10.1007/s10508-0069104-9)

35 Smith YL, Van Goozen SH \& Cohen-Kettenis PT. Adolescents with gender identity disorder who were accepted or rejected for sex reassignment surgery: a prospective follow up study. Journal of the American Academy for Child and Adolescent Psychiatry 200140 472-481. (doi:10.1097/00004583-200104000-00017)

36 De Cuypere G, Elaut E, Heylens G, Van Maele G, Selvaggi G, T'Sjoen G, Rubens R, Hoebeke P \& Monstrey S. Long term follow up: psychosocial outcome of Belgian transsexuals after sex reassignment surgery. Sexologies $2006 \quad 15 \quad 126-133$. (doi:10.1016/j.sexol.2006.04.002)

Received 15 June 2013

Revised version received 15 July 2013

Accepted 30 July 2013 